\title{
Study of maternal and fetal outcome in dengue fever complicating pregnancy
}

\author{
Medarametla Vijayasree \\ Correspondence: Dr Medarametla Vijayasree. Professor. Department of Obstetrics and \\ Gynaecology, Mamata General Hospital, Khammam, Telangana. Email - \\ hospitalstelangana@gmail.com
}

Distributed under Attribution-NonCommercial - Share Alike 4.0 International (CC BY-NC-SA 4.0)

\begin{abstract}
Aim: To study the maternal and fetal outcome in antenatal mothers who were suffering from dengue fever. Methods: A prospective analysis of 56 pregnant women admitted in obstetric ward with dengue fever over a period of 12 months was done and results were observed and documented. Analysis was done with respect to age of patient, gestational age of pregnancy, complications at presentation, laboratory diagnosis, platelet counts and treatment offered. Outcome of pregnancy like abortion, pre-term delivery, term delivery, birth weight and condition of fetus at birth were noted. Maternal mortality and morbidity were also noted. Results: Majority of the patients were in between 26-30 years of age and was in second and third trimesters. The striking feature observed was the presence of severe thrombocytopenia in three fourth of the study population. Eight patients had platelets $<10,000$ cells $/ \mathrm{mm}^{3}$ and all of them received massive platelet transfusions. Thirty six patients had platelet count in between 10,000 to $50,000 \mathrm{cells} / \mathrm{mm}^{3}$, only 20 patients received $4-5$ units of platelet transfusions. In addition, coexistence of other vector borne diseases was also noted. Other associated complications are: dengue hemorrhagic fever (12), pregnancy induced hypertention (12), disseminated intravascular coagulation (4), respiratory stridor (4) and malaria (4) with dengue fever. Most of them had a term vaginal delivery and some had caesarian section. Eight of them had abortion. Conclusion: Most cases required only conservative treatment. Women who went into labour required platelet transfusion. Outcome seemed to correlate with gestational age of occurrence of dengue fever.
\end{abstract}

Keywords: Dengue fever, severe thrombocytopenia, pregnancy.

Dengue fever is a viral disease spread by Aedes Aegypti mosquito. It is more common in children but with increasing rate of adult dengue fever victims, the number of infected pregnant women has also increased. In most of the cases of dengue fever in pregnancy, no serious harm has been noted. Treatment includes proper hydration, antipyretics and careful monitoring. Only case reports and case series have been reported and there is no sufficient data regarding effects of dengue fever in pregnancy ${ }^{2}$. Available literature reveals an increased incidence of pre-term deliveries, low birth weight babies, pre-eclampsia and increased number of caesarean sections. Vertical transmission was also noted. During the dengue epidemic in our region, we came across many pregnant women suffering from dengue fever. With this background, we analysed pregnant women with dengue

Received: $18^{\text {th }}$ September 2019. Accepted: $29^{\text {th }}$ November 2019.

Vijayasree M. Study of maternal and fetal outcome in dengue fever complicating pregnancy. The New Indian Journal of OBGYN. 2020; 6(2): 123-26. 
fever who were admitted in the obstetric ward and determined the adverse effects of fever on pregnancy and the fetal outcome.

\section{Materials and Methods}

A prospective analysis of all the pregnant women with dengue fever was done from January 2017 to December 2017 over a one year period at Mamata general hospital, Khammam, Andhra pradesh, India. Analysis was done with respect to age of patient, gestational age of pregnancy, complications at presentation, laboratory diagnosis, platelet counts and treatment offered. Outcome of pregnancy like abortion, pre-term delivery, term delivery, birth weight and condition of fetus at birth were noted. Maternal mortality and morbidity were also noted. Laboratory diagnosis was done by using Pankio Dengue IgM and IgG antibody testing by ELISA. A positive result of IgM antibodies $>11$ Pankio units was indicative of either an active primary or secondary dengue infection. A positive result of $>22$ Pankio units of $\mathrm{IgG}$ antibodies was indicative of active secondary infection. The sensitivity and specificity of the test were $94 \%$ and $100 \%$ respectively. Data were expressed in contingency tables with number and percentage.

\section{Results}

A total of 56 cases of pregnant women with dengue fever were identified. Majority of the patients were in between 26-30 years of age (Table 1). The mean age of women was $26.07 \pm 4.38$ years. Majority of the patients

Table1: Age-wise distribution $(\mathrm{N}=56)$

\begin{tabular}{ll}
\hline Age of the patient (years) & $\begin{array}{l}\text { No. of pregnant } \\
\text { women }\end{array}$ \\
\hline$<20$ & 4 \\
$20-25$ & 16 \\
$26-30$ & 24 \\
$>30$ & 12 \\
\hline Total & $\mathbf{5 6}$ \\
\hline
\end{tabular}

were in second and third trimesters. Only four patients were found below 12 weeks of gestation and above 36 weeks of gestation (Table 2). The mean gestational age at presentation was $23.2 \pm 8.48$ weeks.

Eight patients had platelets $<10,000$ cells $/ \mathrm{mm}^{3}$ and all of them received platelet transfusions of around 20-22 units. Thirty six patients had platelet count in between 10,000 to 50,000 cells $/ \mathrm{mm}^{3}$. Among them only 20 patients received transfusions. They were given 4 to 5 units of platelets. Twelve patients had platelets in between

Table 2: Gestational age at presentation ( $\mathrm{N}=56$ )

\begin{tabular}{ll}
\hline $\begin{array}{l}\text { Gestational age at which } \\
\text { dengue fever occurred } \\
\text { (weeks) }\end{array}$ & $\begin{array}{l}\text { Number of } \\
\text { pregnant women }\end{array}$ \\
\hline$<13$ & 4 \\
$13-27$ & 24 \\
$28-36$ & 24 \\
$>36$ & 4 \\
\hline Total & $\mathbf{5 6}$
\end{tabular}

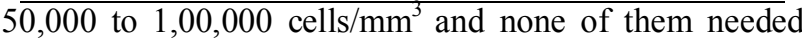
any platelet transfusions (Table 3 ).

Table 3: Platelet count and transfusions received $(\mathrm{N}=56)$

\begin{tabular}{|c|c|c|c|}
\hline $\begin{array}{l}\text { Platelet count on } \\
\text { admission } \\
\left(\text { cell } / \mathbf{m m}^{3}\right)\end{array}$ & $\begin{array}{l}\text { No. of } \\
\text { pregnant } \\
\text { women }\end{array}$ & $\begin{array}{l}\text { No. of } \\
\text { patients } \\
\text { who received } \\
\text { transfusions } \\
\end{array}$ & $\begin{array}{l}\text { No. of } \\
\text { platelet } \\
\text { transfusions }\end{array}$ \\
\hline$<10,000$ & 8 & 8 & 20-22 units \\
\hline $10,000-25,000$ & 20 & 12 & 4-5 units \\
\hline $25,000-50,000$ & 16 & 8 & 4-5 units \\
\hline $50,000-1,00,000$ & 12 & Nil & Nil \\
\hline
\end{tabular}

Out of 56 patients, 20 had full term normal vaginal delivery, 12 underwent full term caesarian section, 4 of them had preterm vaginal delivery, another 4 of them had preterm caesarian section, 4 of them had medical Table - 4: Mode of delivery ( $N=56$ )

\begin{tabular}{ll}
\hline Mode of delivery & Number of women \\
\hline Term vaginal delivery & 20 \\
Term caesarean section & 12 \\
Pre term vaginal delivery & 4 \\
Pre term caesarian section & 4 \\
Medical termination of pregnancy & 4 \\
Spontaneous abortion & 4 \\
\hline Total & $\mathbf{4 8}$ \\
\hline 8/56 of them were lost to follow up \\
\hline termination of pregnancy for eugenic reasons, 4 of them \\
had spontaneous abortion due to hyperpyrexia and 8 of \\
them were lost to follow up (Table 4). \\
\multicolumn{2}{c}{ Twelve patients had dengue haemorrhagic fever, 12 } \\
had associated pregnancy induced hypertention, 4 of them \\
went into disseminated intravascular coagulation, another \\
4 patients were admitted into intensive care unit due to \\
respiratory stridor and malaria was present in 4 patients \\
along with dengue fever (Table 5). Average birth weight
\end{tabular}


Table 5: Associated complications along with dengue fever in pregnancy $(\mathrm{N}=56)$

\begin{tabular}{ll}
\hline Complications & Number of cases \\
\hline Pregnancy induced hypertension & 12 \\
Dengue haemorrhagic fever & 12 \\
Disseminated intravascular coagulation & 4 \\
Dengue with malaria & 4 \\
Post-operative respiratory stridor & 4 \\
\hline Total & $\mathbf{3 6}$ \\
\hline was 2.4 Kgs and there was no evidence of dengue fever in \\
the neonates. \\
Discussion
\end{tabular}

Fever with thrombocytopenia during pregnancy causes panic among the obstetricians. The main fear is the occurrence of dengue haemorrhagic shock or profuse bleeding. Of the 56 women with dengue fever in pregnancy, primary dengue was seen in only four individuals where both $\operatorname{IgG}$ and $\operatorname{IgM}$ were initially negative and paired sera testing taken after two weeks found to be positive and secondary dengue was found in the remaining 52 cases.

Hyperendemic areas are associated with increased probability of secondary infection and occurrence of virulent strains ${ }^{3}$. The presentation was mostly with fever and myalgia. Abdominal pain and vomiting were also seen in a few cases.

Some women presented with bleeding tendencies. The mean age of women was $26.07 \pm 4.38$ years, the youngest being 19 years and the oldest being 35 years. The mean gestational age at presentation was $23.2 \pm 8.48$ weeks with the lowest being 8 weeks and the highest being 38 weeks. Early or late onset of dengue fever in pregnancy appeared to have a bad prognosis. Eight women presented in early pregnancy, four in first trimester in between 8 to 10 weeks and had spontaneous abortion one week later and the other four were in the second trimester presenting at 18 to 20 weeks of gestation. Among them four woman were diagnosed to have malaria with Plasmodium Vivax infection and coincident dengue fever at 18 weeks of gestation. In hyperendemic areas, dengue with malaria may coexist as reported in the literature ${ }^{4}$. Two patients had prolonged fever for 3 weeks. An anomaly scan at 20 wk of gestation showed extensive multiple myocardial calcifications and medical termination of pregnancy was done. Autopsy of the fetus revealed myocardial infarction. Congenital anomaly noted in this case was probably due to the high fever causing hypoxic ischemia. Very few cases of antenatal myocardial calcification in the fetus have been noted in literature. TORCH infection, hypoxia, chromosomal abnormalities have been described as etiological factors ${ }^{5}$. The number of women who presented beyond 31 weeks was 28 out of 56 . Twelve of them had evidence of pregnancy induced hypertension and presented with bleeding tendencies. Six of them were referred as bleeding gums with epistaxis, four of them had melena and one of them had bleeding from intravenous line.

Haemorrhagic complications like primary pulmonary hypertension and abruption have been described in the various studies. There has been one case of severe preeclampsia with dengue haemorrhagic fever requiring 26 units of platelets and another 19-yr old girl who also had Dengue haemorrhagic fever requiring 10 units of platelets before delivery ${ }^{6,7}$ was also documented. None of the studies mentioned platelet counts. In our study, there were eight pregnant women who received massive transfusion of platelets. All the women who were diagnosed to have dengue fever in the second trimester and four of them seen after 31 wk of gestation had an uneventful course. These patients were treated conservatively and discharged. The striking feature among most of these women was severe thrombocytopenia (platelet count of $<50,000 \mathrm{cell} / \mathrm{mm}^{3}$ ) which was seen in 44 out of 56 women of which eight women had platelet counts $<10,000$ cell $/ \mathrm{mm}^{3}$. The fall in platelet count was rapid and progressive initially. Platelet transfusion was done only if the mother went into labour or had any bleeding tendencies or if she was posted for caesarean section. The minimum platelet count required in such conditions was 50,000 cells $/ \mathrm{mm}^{3}$. The dengue haemorrhagic fever (DHF) was seen in twelve individuals; however, there was no case of dengue shock syndrome (DSS). DHF was diagnosed when they had fever with ultrasound evidence of pleural effusion, ascites or gall bladder thickening.

Low birth weight ${ }^{8}$ and pre-term deliveries ${ }^{9}$ have been noted in various studies. The average birth weight in our babies was $2.4 \mathrm{Kgs}$ and thirty two women delivered at or beyond 36 weeks of gestation. We found that mothers who had dengue fever in the first half of pregnancy had average weight babies. However, if the fever occurred beyond 34 weeks, the birth weight was above average. 
Numbers were too small to be of any statistical significance. The average incubation period of dengue fever is estimated to be about 7 days. Dengue infection in the neonate has been reported in many studies ${ }^{10,11}$. In our study all the babies were asymptomatic at birth except two who had fever and was found to be dengue negative. Dengue serology was not performed on all the new born babies and hence no comment could be made on vertical transmission. However, studies conducted in other parts of India, Thailand and Colombia failed to find evidence of vertical transmission among their study subjects ${ }^{12}$. Ismail et $\mathrm{al}^{13}$ states a maternal mortality rate of $2.6 \%$. Although morbidity like DIC, PIH, respiratory stridor and prolonged fever were noted in our study, there was no maternal death.

\section{Conclusion}

Dengue fever in pregnancy most often is treated conservatively. Platelet count may fall rapidly but no active intervention required unless patient is in labour or has bleeding disorder. Severe thrombocytopenia requiring prompt resuscitation with blood and blood products prior to and during delivery, was a key point in successful outcome of individuals having platelet count of $<20,000$ cells $/ \mathrm{mm}^{3}$.

\section{Conflict of interest: None. Disclaimer: Nil.}

\section{References}

1. Phupong V. Dengue fever in pregnancy: a case report. BMC Pregnancy Childbirth. 2001; 1: 7.

2. Pouliot SH. Maternal dengue \& pregnancy outcome - a symptomatic review. Obstet \& Gynaecol Surv. 2010; 65: 107-18.

3. Centers for Disease Control and Prevention. Dengue fever - Yellow book traveller's health. Atlanta: Centers for Disease Control and Prevention; c2008.

4. Ali NN. Dengue fever in malaria endemic areas. J Coll Physicians Surv Pak. 2006; 16(5): 340-2.
5. Chan YF, Sanpson A. Massive myocardial calcification in second trimester fetus, antenatal detection and causes. J Ultrasouns Obstet Gynaecol. 2005; 25: 193-6.

6. Bunyavejchevin S, Tanawattanacharoen S, Taechakraichana N,Thisyakorn U, Tannirandorn Y, Limpaphayom K. Dengue hemorrhagic fever during pregnancy: antepartum, intrapartum and postpartum management. J Obstet Gynaecol Res. 1997; 23: 445-8.

7. Singh N, Sharma K, Dadhwal V, Mittal S, Selvi AS. A successful management of dengue fever in pregnancy: report of two cases. Indian $\mathrm{J}$ Med Microbiol. 2008; 26: 377-80.

8. Basurko C, Carles G, Youssef M, Guindi WE. Maternal and foetal consequences of dengue fever during pregnancy. Eur J Obstet Gynaecol Reprod Biol. 2009; 147: 29-32.

9. Waduge R, Malavige GN, Pradeepan M, Wijeyaratne CN,Fernando S, Seneviratne SL. Dengue infection during pregnancy: a case series from Sri Lanka and review of literature. J ClinVirol. 2006; 37: 27-33.

10. Maroun S, Marliere R, Barcellus R, Claudia N, Barbosall L, Jose RM, et al. Case report: vertical dengue infection. J Pediatr. 2008; 84: 556-9.

11. Thaitumyanoa P, Thisyakorn U, Deerojnawong J, Bruce LI. Dengue infection complicated by severe hemorrhage and vertical transmission in a parturient woman. Clin Infect Dis. 1994; 18: 248-9.

12. Chye JK, Lim CT, Ng KB, Lim JM, George R, Lam SK. Vertical transmission of dengue. Clin Infect Dis. 1997; 25: 1374-7.

13. Ismail NA, Kampan N, Mahdy ZA, Jamil MA, Razi ZR. Dengue in pregnancy. Southeast Asian J Trop Med Public Health. 2006; 37(4): 681-3

\footnotetext{
Medarametla Vijayasree ${ }^{1}$

${ }^{1}$ Professor. Department of Obstetrics and Gynaecology, Mamata General Hospital, Khammam, Telangana, India.
} 